\title{
School Board Politics, School District Size, and the Bargaining Power of Teachers' Unions
}

\author{
Heather Rose \\ Public Policy Institute of California \\ Email: rose@ppic.org \\ Jon Sonstelie \\ University of California, Santa Barbara \\ Email: jon@econ.ucsb.edu
}

\begin{abstract}
August 2004
For helpful comments, we thank Eric Brunner, Caroline Hoxby, Chris Jepsen, Peter Kuhn, Hamp Lankford, Larry Kenny, David Neumark, Chris Stoddard, Perry Shapiro, and seminar participants at Claremont, Princeton, UCSB, and NBER.
\end{abstract}




\title{
School Board Politics, School District Size, and the Bargaining Power of Teachers' Unions
}

\begin{abstract}
This paper develops a public choice model of the bargaining power of teachers' unions. The model predicts that the power of the unions rises with the number of eligible voters in a district. As a bargaining outcome reflecting this power, we use the experience premium for teachers. The premium is defined as the difference in salary between experienced and inexperienced teachers. For a sample of 771 California school districts in 1999-2000, a district's premium is positively related to the number of voters, a finding consistent with the model's prediction.
\end{abstract}




\section{Introduction}

The unionization of teachers has been one of the most significant trends in public education over the last thirty years. Several studies have examined the effect of this trend on teachers' salaries, class sizes, working conditions, and educational productivity. For example, Baugh and Stone (1982) compare the salaries of teachers before and after they are represented by a union. Eberts and Stone (1987) compare the productivity of unionized public schools with the productivity of non-unionized schools. Kleiner and Petree (1988) estimate how average teacher salary and student achievement in states are related to the percentage of teachers in each state who are unionized. Hoxby (1996) compares school inputs and high school drop-out rates in unionized districts with inputs and drop-out rates in nonunionized districts. Stone (2002) provides a thorough summary of this literature.

Studies in this literature share a common method. They compare outcomes in unionized school districts with outcomes in non-unionized districts. This method has been fruitful, but it directs attention away from the differential effects of unionization. Unions may be more powerful in some districts than in others and thus relatively more successful in achieving outcomes beneficial to their members.

Unlike the previous research, this paper focuses on these differential effects. We hypothesize that teachers' unions will be more powerful in large districts than in small ones. We derive this hypothesis from a public choice model of the political power of teachers' unions and homeowners. As Fischel (2001) observes, homeowners are the residual claimants of the surplus produced by public schools. If a public school district produces educational services more valuable than the taxes necessary to finance those services, it enhances the value of homes within its boundaries. As a consequence, homeowners have a powerful incentive to protect and improve the quality of their local public schools. Teachers' unions seek to divert some of that public school surplus to their members. If a union secures higher salaries for its members than would be necessary to keep them employed in the district, it directs resources away from other useful activities and thus reduces the surplus that is capitalized into home values.

The competing interests of teachers and homeowners are played out in school board politics. The school board hires the administrators who represent the district in collective bargaining. If the teachers' 
union can help to elect school board members sympathetic to its interests, it will face relatively sympathetic administrators in collective bargaining. Unions can help elect school board members by various activities, including endorsements, campaign contributions, and neighborhood canvassing. Homeowners can employ the same strategies in support of candidates more sympathetic to their interests. In this political competition, homeowners are at a particular disadvantage. Campaign contributions and other effort on behalf of a school board candidate are a public good to the supporters of that candidate. As a consequence, each homeowner has an incentive to free-ride on the effort of others, leading to a total effort that is less than collectively optimal. Teachers face the same problem, but they have a method for overcoming it. They can organize a union and tax themselves through union fees to support candidates aligned with their interests.

This political disadvantage for homeowners is particularly acute in large districts. The effort required to influence school board elections increases with the number of eligible voters in a district. A teachers' union can meet this increased demand because union membership grows with district size and the funds that a union can raise from its members increase with its membership. In contrast, because the free-rider problem is more difficult to overcome in large groups, the support homeowners can muster for candidates they favor is unlikely to grow as rapidly as the size of the district increases. Thus, the relative power of the teachers' union in collective bargaining should increase with district size as measured by the number of eligible voters in the district.

The relative power of the teachers' union should be reflected in teachers' salaries. In the typical contract between a public school district and its teachers' union, the salary of a teacher is determined solely by his or her education and years of teaching experience. A salary schedule with a high premium for experience rewards teachers who have been employed by a district for many years and are unlikely to leave it. A high premium creates a rent for senior teachers, which is not in the best interests of homeowners. We maintain, therefore, that the size of a district's experience premium is a reflection of the power of its teachers' union, and we test the hypothesis that these premiums increase with the number of eligible voters in a district. 
The next section develops a model of collective bargaining that captures the essential elements outlined above. We then present empirical evidence on the experience premium in 771 unionized California school districts in 1999-2000. We find that a school district's experience premium is positively and significantly related to the size of the district, a result consistent with the predictions of our public choice model.

\section{A Model of Collective Bargaining}

Our objective is a model relating the political power of the teachers' union to the salary schedule that emerges from collective bargaining. We proceed in two steps. First, we develop a model of collective bargaining in which the salary schedule is a function of the political power of the teachers' union. Second, given that function, we develop a model that determines the political power of the union.

\section{A Model of Collective Bargaining Given the Union's Political Power}

We develop a one-period model in which teachers currently employed in a school district negotiate with district administrators over working conditions and the salary schedule. After the contract is negotiated, the district may hire additional teachers whose salary is determined by the new contract. We refer to teachers employed in the district before negotiations as current teachers and denote the number of these teachers per pupil by $m$. We let $n$ denote the total number of teachers per pupil employed in the district after the contract is negotiated, thus $n-m$ is the number of new teachers per pupil.

In a typical contract, a teacher's salary is a function of his or her experience and education. A teacher's education tends to increase with experience, as teachers accumulate educational units over time. To simplify, we assume salary is a linear function of just one factor, which we refer to as experience. This function is $b+\pi e$, where $b$ is the base salary, $e$ is years of experience, and $\pi$ is the salary premium per year of experience. The per-pupil cost of teacher compensation is thus $b n+\mathrm{E} \pi$, where $\mathrm{E}$ is the total years of experience for all teachers in the district divided by the number of pupils. 
The district's budget constraint is

$$
x+b n+E \pi=y,
$$

where $x$ is per-pupil expenditures on goods and services other than teacher compensation and $y$ is revenue per pupil. Experience per pupil, $E$, is the price of the experience premium.

We assume throughout that revenue per pupil, $y$, is exogenous to the district. This assumption reflects the reality of California's school finance system in which the state determines each district's revenue, and districts then bargain with their unions given that revenue. In that context, the political power of the union is focused on allocating revenue among competing demands. In states where local school districts may raise their own tax revenue by raising local taxes, the union may also use its political power to encourage local voters to support tax increases. Courant, Gramlich, and Rubinfeld (1979) analyze this process.

Models of collective bargaining employ one of two general approaches (Farber, 1986). In one approach, employers and unions bargain over wages, and the employer then chooses the level of employment. In the second approach, employers and unions bargain over both wages and employment. The second approach yields an efficient contract, one in which the utility of employees cannot increase without decreasing the utility of their employer. The first approach does not generally yield an efficient contract. In the case of California school districts and their teachers' unions, bargaining occurs over both the salary schedule and maximum class sizes. Maximum class sizes determine the minimum number of teachers, and in that sense districts and teachers negotiate over both salaries and employment. In what follows, we assume that districts and unions bargain directly over the salary schedule $(b$ and $\pi)$ and employment $(n)$. Because of the budget constraint, bargaining over salary schedules and employment also means that districts and unions are implicitly bargaining over the level of expenditures on goods and services other than teachers' salaries $(x)$.

The union represents the interests of current teachers. These teachers are concerned about working conditions, so they prefer a higher teacher-pupil ratio and higher non-teacher expenditures. They 
also prefer higher salaries, which translates into a preference for a higher base salary and a higher experience premium. Current teachers may differ on the marginal value of the experience premium, however. Relative to teachers with many years of experience, young teachers may be more willing to trade improved working conditions for a decrease in the experience premium.

To represent their interests in collective bargaining, current teachers choose a negotiator to evaluate options at the bargaining table. Choosing a negotiator is essentially choosing a utility function to evaluate bargaining options. In general, this is a complicated issue, but we simplify it with the following assumption: For a teacher with $e$ years of experience, utility is $f(x, n)+b+\pi e$. That is, the utility a teacher derives from a contract is his or her salary under that contract $(b+\pi e)$ plus a value for working conditions under the contract $(f(x, n))$. The utility of the salary schedule is separable from the utility of working conditions, the utility of working conditions is the same for everyone, and the utility of the salary schedule differs among teachers according to their experience. More experienced teachers place a higher marginal value on the experience premium.

Under that assumption, the choice of a union negotiator comes down to the choice of the experience level to represent the preferences of union members. Following the example of Farber (1978), we assume that this choice is dictated by the median voter. Suppose there are two candidates for negotiator, each proposing to use a different experience level to evaluate bargaining options. All teachers with more experience than the higher of the two levels will prefer the candidate proposing the higher level. On the other hand, all teachers with less experience than the lower of the two proposed levels will prefer the candidate proposing the lower level. Consequently, in an election to be union negotiator, a candidate proposing the median experience level will defeat a candidate proposing any other level. We assume, therefore, that the utility function of the negotiator for the teachers' union is

$$
U^{t}(x, n, b, \pi, \tilde{e})=f(x, n)+b+\pi \tilde{e},
$$

where $\tilde{e}$ is the median experience of current teachers. 
The school district's representative at the negotiating table is ultimately responsible to the elected school board, which gives the union another avenue to affect collective bargaining outcomes. As Freeman (1986) puts it, "public sector employees help elect both the executive and legislative branches of government and thus play a role in determining the agenda for those facing them at the bargaining table." In this particular case, we assume that the district negotiator represents two fundamental interests: the district's homeowners and its teachers' union. In many respects, the interests of homeowners are congruent with the interests of the teachers' union. Everything else equal, homeowners prefer that their schools have higher non-teacher expenditures, higher teacher-pupil ratios, and better new teachers, all factors that improve school quality and enhance home values. We assume that all homeowners have the same utility, which we denote by $u(x, n, q)$, where $q$ is the quality of new teachers the district is able to attract.

Because higher salaries help attract a better pool of applicants for open positions (Loeb and Page (2000)), the preference of homeowners for higher quality teachers translates into a preference for higher starting salaries and higher experience premiums. We let $w$ denote the salary that a teacher could earn in alternative employment, and we assume that the quality of new teachers a district can attract is positively related to its working conditions and salaries and negatively related to this alternative salary. We denote this relationship by the function $q(x, n, b, \pi, w)$. The utility of homeowners is therefore

$$
U^{h}(x, n, b, \pi, w)=u(x, n, q(x, n, b, \pi, w)) .
$$

In representing the school board, the district negotiator must balance the interests of homeowners and the teachers' union. To capture this balancing act, we assume that the district negotiator evaluates bargaining outcomes by the utility function

$$
U^{d}=\lambda U^{t}+(1-\lambda) U^{h},
$$

where $\lambda$ reflects the relative power of the teachers' union in school board politics.

Collective bargaining is assumed to be efficient, which implies that the bargaining outcome can be represented as the choice of $x, n, b$, and $\pi$ to maximize a weighted sum of $U^{d}$ and $U^{t}$. Suppose that 
the two utility functions have equal weight in this sum. Then the weighted sum can be represented in terms of the fundamental interests of homeowners and the union as

$$
U=U^{t}+U^{d}=(1+\lambda) U^{t}+(1-\lambda) U^{h}
$$

The contract that emerges from collective bargaining maximizes $U$ subject to the budget constraint in (1). In what follows, we first explore the comparative statics of this maximization problem assuming that $\lambda$ is fixed. We then turn to the determination of $\lambda$.

The problem of maximizing $U$ subject to the budget constraint in (1) is similar to the maximization problem in the standard theory of consumer demand. The main difference is that the budget constraint in our case is non-linear because collective bargaining determines both salary and employment. This non-linearity makes some comparative statics results different than in the standard theory of consumer demand. These results are derived in the appendix.

Our main interest is in how the power of the union affects bargaining outcomes. If the union is stronger in one district than another, how do we expect bargaining outcomes to differ between the two districts? For our empirical work, what bargaining outcomes can we focus on as indicators of the relative power of a district's teachers' union? Our model has four outcomes, and we have argued that the utilities of both teachers and homeowners are increasing in all four. As a consequence, our model has no absolute indicators of union power. There is no outcome for which one party will always prefer a higher level and the other will always prefer a lower level, no matter what tradeoffs exist. In our model, indicators of union power come down to the relative value the two parties place on the four outcomes. Are certain outcomes less valuable to homeowners than to teachers?

We argue that the experience premium is such an outcome. To put our argument in its simplest terms, consider two salary schedules, each with the same ability to attract high quality teachers to the district. One schedule has a high base salary and a low experience premium; the other has a low base and a high premium. The schedule with the high premium directs more district resources to teachers who are already in the district and unlikely to leave it. It creates a rent for those teachers. As a consequence, 
current teachers are likely to favor that schedule. For the same reason, homeowners are likely to favor the schedule with the lower premium. These conflicting interests exemplify the exit-voice analysis of union behavior (Freeman (1976)).

This simple characterization of the issue ignores several other possibilities. One possibility is that experienced teachers are more effective than inexperienced teachers and thus command a premium. Lankford and Wyckoff (1997) and Ballou and Podgursky (2002) consider that possibility but reject it on empirical grounds. Teachers with three or four years of experience are more effective than new teachers, but experience beyond that point seems to add little to their effectiveness. Consistent with that finding, most teachers' contracts put a limit on the credit a teacher receives for years of teaching experience in another school district, suggesting that experience by itself is not valued by districts.

Another possible rationale for the experience premium follows from the analysis of work-life incentive schemes by Lazear (1995). Employers may offer a positively sloped experience-wage profile to give workers an incentive to exert effort throughout their careers. The possibility of dismissal for inferior performance acts as an incentive, but it becomes less effective as the years left before retirement decline. By offering a higher salary in those years, the employer counteracts this tendency, maintaining the incentive effect of possible dismissal. Lazaer's explanation is similar to the theory of efficiency wages in that employers pay workers a wage in excess of their marginal product to encourage them to exert sufficient effort. Although this incentive theory may provide a good explanation in many cases, we do not believe it applies to public school teachers in California because they have job security after a threeyear probationary period.

Another rationale for an experience premium is turnover costs. School districts train new teachers, and it is therefore costly to lose them. By offering a contract in which salary is less than a teacher's true value in the first few years of employment but greater than the value in subsequent years, the district tends to screen out teachers who are likely to move within a few years. Ballou and Podgursky (2002) also consider this rationale for an experience premium, but they conclude that the turnover costs in teaching are not large enough to justify the magnitude of experience premiums typically observed. 
This conclusion suggests a useful way to think about how homeowners and teachers are likely to view the tradeoffs between the base salary and the experience premium. If the base salary is high and the experience premium is low, turnover costs will be relatively high. An increase in the premium accompanied by a decrease in the base will reduce turnover costs in the future, but it will also increase the salary of experienced teachers who are unlikely to leave. Thus, to homeowners, a rent to current teachers is the cost of reducing future turnover. Current teachers will see this rent as a benefit, however. Thus, homeowners and teachers are likely to see very different tradeoffs between the experience premium and other contract outcomes. For a given increase in the experience premium, experienced teachers will be willing to sacrifice a larger decrease in, say, non-teacher expenditures than homeowners are willing to sacrifice. As a consequence, the experience premium that is actually negotiated reflects the power of the teachers' union.

Kuhn (1988) offers another, complementary rationale for experience premiums. According to that rationale, a union with seniority rules about layoffs and hiring is equivalent to a monopoly that can charge different prices to different customers. The monopoly charges a higher price to customers who value its product most highly, thereby extracting some of their consumer surplus. If a firm has a declining marginal product of labor, its union can negotiate a higher price for the workers the firm must lay off last and hire first, thereby extracting some of the firm's rent. This rationale for the experience premium has the same qualitative predictions as the rationale based on turnover costs. The more power the union has in collective bargaining, the more rent it can extract, and thus the higher the experience premium. Consistent with that prediction, Ballou and Podgursky (2002) examine salary schedules in 165 large school districts in 1989-90 and find that the experience premium is larger in unionized districts. 
In our model, the relative importance the union attaches to the salary premium is captured in the following assumption:

$$
\frac{U_{\pi}^{t}}{U_{x}^{t}}>\frac{U_{\pi}^{h}}{U_{x}^{h}}, \frac{U_{\pi}^{t}}{U_{n}^{t}}>\frac{U_{\pi}^{h}}{U_{n}^{h}}, \text { and } \frac{U_{\pi}^{t}}{U_{b}^{t}}>\frac{U_{\pi}^{h}}{U_{b}^{h}},
$$

where the subscripts represent partial derivatives. With that assumption and the assumption that the experience premium is a substitute for all other bargaining outcomes, we can show that

$$
\frac{\partial \pi}{\partial \lambda} \geq 0
$$

That is, an increase in the power of the teachers' union increases the experience premium. The proof of this proposition is given in the appendix.

According to the comparative statics of our model, the experience premium is also a function of two other important variables. The first is years of teacher experience per pupil, $E$, which is the price of the experience premium. If the experience premium is a normal good, an increase in its price decreases the experience premium, that is,

$$
\frac{\partial \pi}{\partial E} \leq 0
$$

On the other hand, an increase in the median experience of current teachers, $\tilde{e}$, increases the marginal value that teachers place on the experience premium, which increases the premium. As shown in the appendix,

$$
\frac{\partial \pi}{\partial \widetilde{e}} \geq 0
$$

As a district's teaching staff matures, the increase in median experience will be accompanied by an increase in average experience, yielding offsetting effects on the experience premium. In a panel of school districts, Babcock and Engberg (1999) found that median experience is associated with higher premiums, suggesting that the second effect dominates. In our empirical analysis, we include both 
median experience and teacher experience per pupil in an attempt to sort out the relative magnitudes of those offsetting effects.

\section{A Model of the Union's Political Power}

In our model, the utility of the district negotiator is a linear combination of the utilities of homeowners and the teachers' union, a representation embodying Freeman's point that public sector unions can use the political process to influence the agenda of those facing them across the bargaining table. O'Brien (1992, 1994, and 1996) examines this point in the case of unions of police officers and firefighters, where the relevant political process is the election of mayors and city council members. In the case of teachers' unions, the relevant process is the election of school board members, who govern school districts. Though this process has not been studied intensively, we are fortunate to have the results from a national survey of school board members (Hess (2002)).

The survey confirms many common beliefs. School board service is not a full-time job, and few members are compensated for their service. Despite some newsworthy exceptions, 96 percent of school board members are elected, not appointed. School board elections have relatively low visibility, as evidenced by voter turnout. When held on the same day as a national or statewide election, turnout in school board elections averages 44 percent. When held as a special election, turnout averages only 26 percent.

Like candidates for other public offices, school board candidates must make themselves known to voters. Candidates can advertise themselves through mailings, phone banks, and door-to-door canvassing. The cost of these activities increases with district size. In districts with fewer than 5,000 students, 95 percent of candidates in the Hess survey spent less than $\$ 1,000$ on their campaigns. In districts with more than 25,000 students, however, 25 percent of candidates spent more than $\$ 10,000$. An 
extreme case is the May 2003 election of four board members in Los Angeles Unified School District. Candidates in those four races spent a total of $\$ 2.7$ million. $^{1}$

The sources of these funds also vary with district size. In small districts, campaign expenses are low enough so that most candidates can meet them through their own personal means. In districts with fewer than 5,000 students, 45 percent of candidates in the Hess survey reported that at least half of their campaign expenditures was met through personal wealth. In contrast, for districts with more than 25,000 students, only 30 percent of school board members reported that the majority of their contributions came from personal wealth. In these large school districts, school board candidates turned to other sources for campaign contributions. For the source of at least 50 percent of their contributions, 31 percent of respondents in large districts listed "family and friends," 21 percent listed employee unions, and 19 percent listed the business community.

Teachers' unions can do more than contribute money, particularly because teachers can make very effective campaign volunteers. In his survey of 526 school board candidates in 256 California school districts, Moe (2003) confirms Hess's findings about campaign contributions and adds details about other activities of teachers' unions in school board elections. Confirming Hess's findings, unions were a more important source of campaign contributions in large districts than in small districts. In districts with fewer than 5,000 students, teachers' unions contributed to school board candidates in 22 percent of districts. In districts larger than 25,000 students, teachers' unions contributed to candidates in 94 percent of districts. In addition, teachers' unions recruited candidates for school board in 52 percent of large districts, but in only 13 percent of small districts. Unions made phone calls in support of candidates in 97 percent of large districts, as opposed to 21 percent in small districts. In terms of door-to-door campaigning, the difference was 68 percent in large districts and 18 percent in small districts. Not only were teachers' unions more likely to contribute money in large districts than small, they were also more likely to work directly in support of school board candidates they favored.

\footnotetext{
${ }^{1}$ See the website of the Los Angeles City Ethics Commission: http://ethics.lacity.org.
} 
These activities create the impression among school board candidates that unions are a more significant political factor in large districts than in small districts. Hess asked school board members whether various groups were "active" in school board elections. In districts with fewer than 5,000 students, 44 percent of respondents reported that their teachers' unions were active in their district. In districts with more than 25,000, 80 percent reported that their teachers' unions were active. Moe asked school board candidates whether the teachers' union was "important" in their districts. In small districts, the union was important in 52 percent of districts. In large districts, it was important in 82 percent of districts.

These results are consistent with a public goods theory of school board elections. Candidates for school board must spend time and effort introducing themselves to voters. In small districts, these costs are small, and candidates can meet them from personal time and wealth. As districts increase in size and campaign costs increase, candidates begin to look to others in the community for support. Individual homeowners are a natural source of support because they have much at stake in high quality schools. However, campaign contributions are a public good, and individual homeowners therefore have an incentive to be free-riders. This incentive is particularly strong in large districts, where any one homeowner's contributions would have very little effect on a candidate's campaign and where individual homeowners may feel relatively anonymous and thus insulated from the social pressure to support a common cause. Campaign contributions are also a public good for individual teachers, but the teachers' union gives them a way to overcome the free-rider problem. Through union dues, teachers can tax themselves to support common objectives, including electing candidates who are likely to be sympathetic to their interests. As the Hess survey makes clear, family, friends, and the business community are also sources of support. Among those possible sources, however, unions are uniquely equipped to respond to the need for campaign contributions because the revenue a union collects from its members increases with the size of the school district. As a consequence, teachers' unions are more politically powerful in large school districts. 
To formalize these ideas, we construct a simple model of school board elections. In the model, two candidates run against each other for a position on the school board. One candidate is sympathetic to the interests of homeowners, and the other is sympathetic to the interests of the teachers' union. The teachers' union and homeowners can apply effort in support of their candidate for school board. To be specific, we refer to this effort as campaign contributions, although we envision a broader array of political activities than contributions. The more a union contributes to the candidates it supports, the more effective are the campaigns of those candidates, the larger is the vote in favor of those candidates, and the greater is the political power of the union. Homeowners have the same possibilities to influence electoral outcomes; the more homeowners contribute, the less is the political power of the union.

To capture the notion that campaign costs increase with district size, we measure campaign contributions relative to the number of voters. Specifically, let $c^{t}$ denote the union's total contributions per voter, and let $c^{h}$ denote the homeowners' total contributions per voter. The power of the teachers' union in collective bargaining is positively related to $c^{t}$ and negatively related to $c^{h}$. We also assume that the power of the teachers' union is negatively related to the percentage of eligible voters who are homeowners, a percentage denoted by $\theta$. These assumptions are represented by

$$
\lambda=L\left(\theta, c^{t}, c^{h}\right)
$$

where $L_{\theta}<0, L_{c^{t}}>0$ and $L_{c^{h}}<0$.

The campaign contributions of teachers and homeowners are determined in part by the utility from collective bargaining that each can expect for a given $\lambda$. Let $V^{t}(\lambda)$ be that utility for teachers, and let $V^{h}(\lambda)$ be that utility for homeowners. These are indirect utility functions, the utility resulting from maximizing $U$ subject to the district's budget constraint. The indirect utility of teachers is increasing in $\lambda$, and the indirect utility of homeowners is decreasing in $\lambda$. To simplify subsequent analysis, we assume that these utilities are denominated in terms of the numeraire commodity. 
From the perspective of the teachers' union, the marginal value of contributions depends on its indirect utility function, and it also depends on the contributions of homeowners. Similarly, the marginal value of homeowners' contributions depends in part on the contributions of the teachers' union. We assume the outcome is a Nash equilibrium in which each party's contributions are optimal given the contributions of the other party.

Candidates solicit donations from their supporters. We assume that the homeowners' candidate asks each supporter to contribute a certain amount. Suppose the candidate asks for $p$ from each supporter. Each potential supporter will compare the utility of being a supporter against its cost. The benefit of being a supporter is the increase in $V^{h}$ because the potential supporter's contribution will increase the campaign contributions to the homeowners' candidate and thus decrease the political power of the teachers' union. A supporter also increases the utility of other homeowners, making campaign contributions a public good.

In models of voluntary contributions to a public good, such as Bergstrom, Blume, and Varian (1986), individuals are assumed to ignore the benefit their contributions create for others. However, in experiments with voluntary contributions to a public good, subjects tend to contribute more than dictated by their personal benefit, suggesting that individuals derive some utility from cooperating with others in the provision of a public good (Ledyard, 1995). Experiments also show that this cooperative behavior tends to decline with the size of the group benefiting from a public good. Similarly, in their empirical investigation of voluntary contributions to California public schools, Brunner and Sonstelie (2003) find that parents contribute more than predicted by a rational calculation of their personal benefits, but that contributions per capita decline with the size of the school. To represent this behavior, we also assume that a supporter receives some benefit from the act of supporting his or her favored candidate and that this benefit declines as the number of potential supporters increases. This benefit of cooperating is denoted by the function $B(\theta \mathrm{Z})$, where $Z$ is the number of eligible voters in the district and $B^{\prime}(\theta Z)<0$. 
A potential supporter contributes to a candidate's campaign if the benefits exceed the cost, which is the contribution supporters are asked to make. In equilibrium, therefore, the number of supporters, $s$, equates benefits and costs. After rearranging terms, this equation is

$$
V^{h}\left(L\left(\theta, c^{t}, \frac{p s}{Z}\right)\right)-V^{h}\left(L\left(\theta, c^{t}, \frac{p(s-1)}{Z}\right)\right)=p-B(\theta Z) .
$$

Equation (11) implicitly defines the number of supporters as a function of donations per supporter, the percentage of homeowners, the contributions of the teachers' union, and the number of voters. Let $s=g\left(p, \theta, c^{t}, Z\right)$ denote this function. Holding other variables constant, an increase in the number of eligible voters may increase the number of supporters. However, the number of supporters will increase less than proportionally to the number of voters. That is,

$$
\frac{\partial g}{\partial Z}<\frac{s}{Z}
$$

To see this result, suppose $s$ and $Z$ were to increase proportionally. The difference on the left side of Equation (11) would decline because $V^{h}\left(L\left(\theta, c^{t}, \frac{p s}{Z}\right)\right)$ would not change and because $V^{h}\left(L\left(\theta, c^{t}, \frac{p(s-1)}{Z}\right)\right)$ would increase. In essence, a proportional increase in $s$ and $Z$ decreases the marginal value of any one supporter's contribution. In contrast, the right side of (11) would increase because the benefit of cooperating decreases with $Z$. To restore equality, the number of supporters must decrease.

The more a candidate asks of supporters, the fewer supporters he or she will have. Thus, a candidate must balance donations per supporter against the number of supporters, choosing an amount to ask from supporters that maximizes total contributions. Contributions per voter are thus a function of $c^{t}$, $\theta$, and $Z$. Because this function gives contributions per voter to the homeowners' candidate as a function of contributions per voter to the union's candidate, we refer to it as a reaction function, denoted by $R^{h}\left(c^{t}, \theta, Z\right)$. From the envelope theorem and inequality (12), 


$$
\frac{\partial R^{h}}{\partial Z}<0
$$

Inequality (13) is a key part of our public goods theory of school board elections. For the homeowners' candidate, contributions per voter fall as the number of eligible voters rises.

Our theory does not yield a clear prediction about how homeownership affects contributions. We assume that $\frac{\partial \lambda}{\partial \theta}<0$. That is, an increase in the percentage of homeowners has a direct negative effect on union power, which may affect contributions. However, an increase in $\theta$ exacerbates the free-rider problem for homeowners, potentially offsetting this negative effect.

The other key part of our theory is that the teachers' union has a mechanism for internalizing the benefits of campaign contributions. For teachers, campaign contributions are not voluntary. The union determines a fee for all union members, which funds campaign contributions. Because of this fee, union members share in the cost of campaign contributions, internalizing the external benefits of any one member's contribution. The fee is $\frac{Z c^{t}}{\tau Z}=\tau^{-1} c^{t}$, where $\tau$ is the ratio of current teachers to eligible voters. The price of contributions per voter is therefore $\tau^{-1}$. We assume that the union chooses its contributions by majority rule. Thus, the contributions maximize the utility of the teacher with median experience, who we assume to be the district representative in collective bargaining. That is, campaign contributions maximize

$$
V^{t}\left(L\left(\theta, c^{t}, c^{h}\right)\right)-\tau^{-1} c^{t}
$$

This maximization problem defines the contributions per voter of the teachers' union as a function of the contributions per voter of homeowners, the percentage of homeowners, and the ratio of union members to voters. Let $R^{t}\left(c^{h}, \theta, \tau\right)$ denote this reaction function. 
A Nash equilibrium is obtained when contributions from homeowners and the union satisfy the following two equalities:

$$
\begin{aligned}
& c^{t}=R^{t}\left(c^{h}, \theta, \tau\right) \\
& c^{h}=R^{h}\left(c^{t}, \theta, Z\right) .
\end{aligned}
$$

The comparative statics of this equilibrium require us to make some assumptions about the stability of equilibrium. In particular, we assume that

$$
\frac{\partial R^{t}}{\partial c^{h}}<-\frac{\partial L}{\partial c^{h}} / \frac{\partial L}{\partial c^{t}} \text { and } \frac{\partial R^{h}}{\partial c^{t}}<-\frac{\partial L}{\partial c^{t}} / \frac{\partial L}{\partial c^{h}}
$$

The first condition implies a stable reaction from the union to a change in the contributions of homeowners. For example, if homeowners increase contributions, the union may respond by increasing its own contributions. Condition (16) requires that the union response is not so large that it overwhelms the homeowners' initial increase. In other words, the net effect of the homeowners' initial increase and the union's response is a decrease in union power. The second condition requires an analogous stability condition for the homeowners' reaction function.

The key result from our public choice model concerns the effect on union power of an increase in the number of voters. In particular, an increase in the number of voters will increase the political power of the union, that is,

$$
\frac{\partial \lambda}{\partial Z}>0
$$

The mathematics are outlined in the appendix, but the intuition is straightforward. Holding union contributions per voter constant, an increase in the number of voters decreases contributions per voter to the homeowners' candidate. On the other hand, assuming the number of union members increases in proportion to the number of voters, an increase in the number of voters has no direct effect on the contributions per voter of the teachers' union. The union may react to the decline in homeowner contributions per voter by decreasing its own contributions per voter, which may stimulate a further 
decrease in homeowners' contributions and so on. However, these actions and reactions will only dampen the initial effect; they will not reverse it.

Combining this result with inequality (7),

$$
\frac{\partial \pi}{\partial Z}=\frac{\partial \pi}{\partial \lambda} \frac{\partial \lambda}{\partial Z} \geq 0
$$

an increase in eligible voters enhances the political power of the union which raises the experience premium for teachers. This result forms the basis of our hypothesis test in the next section.

Our model yields one other testable hypothesis. An increase in the ratio of teachers to the voting population decreases the price of contributions for teachers but has no direct effect on contributions for homeowners. Thus an increase in the ratio of teachers to eligible voters enhances the political power of the union, which raises the experience premium. That is,

$$
\frac{\partial \pi}{\partial \tau}=\frac{\partial \pi}{\partial \lambda} \frac{\partial \lambda}{\partial \tau} \geq 0
$$

Our model of political power is simple, but we believe it captures an important point. For a class of citizens with a common interest, such as the homeowners in a school district, political representation is a classic public goods problem that is exacerbated by the size of the political entity. The empirical analysis of Oliver (2000) supports the general idea that participation of individual citizens in the political process declines as the population of the political entity increases. In contrast, because a teachers' union has the power to tax its members, its resources grow proportionally to district size. Thus, we expect the teachers' union to be relatively more powerful in large school districts. Because we maintain that the experience premium in a district is a reflection of the bargaining power of its teachers' union, our theory predicts a positive relationship between a district's experience premium and the number of eligible voters in the district. In the next section, we test that hypothesis.

Of course, such a test can only falsify our hypothesis; it cannot prove that it is correct. Other theories may also predict a positive relationship between the experience premium and district size. Before examining that relationship, it seems worthwhile to consider one particular alternative. Suppose 
that large districts would tend to experience more teacher turnover if they offered the same salary schedule as small districts. In that case, we should expect large districts to respond by creating higher experience premiums than small districts in an attempt to screen out teachers who are most likely to leave after a few years. However, despite this response, teacher turnover should continue to be higher in large districts. That is, given that an increase in the experience premium is costly because it must be paid to teachers who are established in the district and unlikely to leave, large districts would attempt to reduce turnover, but would not eliminate the difference in turnover between large and small districts. Accordingly, one way to separate this alternative explanation from our own is to examine teacher turnover in large and small districts.

This examination has recently been completed by Reed, Rueben, and Barbour (2003). They merged data from the California Commission on Teacher Credentialing with data from the California Employment Development Department to develop employment histories of California teachers credentialed between 1990 and 2000. For each academic year following a teacher's credential, the data reveal whether the teacher continues to work for his or her initial school district. Using this data, Reed and co-authors estimate a hazard model, giving the probability that a new teacher has left his or her initial district in any given subsequent year. The model controls for many characteristics of the teacher and the school district, including the enrollment of the district. Reed and co-authors find that enrollment is negatively and significantly related to the probability of leaving the initial district. Teachers are less likely to leave large districts than small districts, a result inconsistent with the alternative explanation of a positive relationship between school district size and the experience premium. 


\section{Empirical Results}

To test the hypotheses from our collective bargaining model, we use data from California school districts in 1999-2000. In that year, California had 982 districts enrolling nearly 6 million students. According to the California Public Employment Relations Board, teachers in 886 of those districts were represented by a union. Of those 886 districts, 771 reported their salary schedules to the California Department of Education. These 771 districts constitute our sample. The districts excluded from our sample are primarily small in size, enrolling fewer than 4 percent of California students.

For this sample, we estimate a model of the district's experience premium for teachers, $\pi$. The premium is derived from the Salary and Benefits Schedule for the Certificated Bargaining Unit (Form J90) maintained by the California Department of Education. The schedules are a grid in which each column represents a different education level and each row, referred to as a step, represents the years of experience the teacher has within the district. The education levels refer to the teacher's highest degree plus the number of academic semester units earned beyond that degree. Each cell in the grid corresponds to the salary for the given combination of experience and education.

Districts vary in the number of columns in their schedules. At one extreme, some districts have only one column and give no extra salary for additional education. However, many districts have columns for 30, 45, 60, and 75 units beyond a bachelor's degree (BA). Nearly half of the school districts in our sample have 75 units as their final column; another 10 percent have a column for teachers with 90 units beyond a BA. About one-quarter of the districts stop short of that, with a highest column of 60 units. A much smaller share, 10 percent, stop at 45 units. Some districts award higher salaries for the completion of a master's degree. 
Table 1

Average Teacher Salaries, 1999-2000

\begin{tabular}{lccc|c}
\hline & \multicolumn{2}{c|}{ Education Level (Units Beyond a BA) } & \\
\cline { 2 - 3 } & \multicolumn{3}{c}{} & $\begin{array}{c}\text { District } \\
\text { District Max Less } \\
\text { Column 30 }\end{array}$ \\
\hline Step 1 & 30 & 60 & Maximum & $\$ 2,932$ \\
Step 11 & $\$ 31,913$ & $\$ 33,904$ & $\$ 34,844$ & 6,533 \\
Step 21 & 42,975 & 48,009 & 49,508 & 10,702 \\
\hline Step 21 less step 1 & 44,677 & 52,571 & 55,379 & \\
\hline
\end{tabular}

Table 1 shows average salaries for districts in our sample. These salaries are reported for three experience levels and three education levels. The first column shows average salaries for teachers with a bachelor's degree and 30 units of additional coursework. This education level is typical of fully credentialed teachers just entering the workforce. We measure a district's base salary as the salary of a teacher at step one in that first column. In 1999-2000, districts offered an average base salary of $\$ 31,913$. The final column in Table 1 shows the average salaries for each district's highest column that does not require a master's degree.

Several measures of an experience premium are possible. The primary measure we use is the difference between the base salary and the salary of a teacher with twenty years of experience (a teacher at step 21) at the highest column in the district that does not require a master's degree. This twenty-year salary averaged $\$ 55,379$, for a total gain of $\$ 23,466$. We divide this gain by twenty to yield an average annual experience premium. In 1999-2000, the annual experience premium averaged $\$ 1,173$. This twenty-year premium smoothes out some non-linearities in the salary schedule. For example, the returns to education and experience taper off as experience and education rise. If teachers acquire 60 units of education after ten years of experience, their salaries increase by $\$ 17,000$, nearly two-thirds of the total increase over the 20-year span. However, the ten-year premium is highly correlated with the twenty-year premium $(\rho=0.7)$. When we estimate our model with the ten-year premium, the results are similar to the results using the twenty-year premium. 
Table 2

Summary Statistics

(Number of Observations $=771$ )

\begin{tabular}{lrr}
\hline & Mean & $\begin{array}{r}\text { Standard } \\
\text { Deviation }\end{array}$ \\
\hline Experience premium $(\$ 1,000)$ & 1.173 & 0.205 \\
Eligible voters (thousands) & 33.201 & 97.891 \\
Students per eligible voter & 0.254 & 0.165 \\
Percentage of homeowners & 0.651 & 0.123 \\
Regional salary $(\$ 1,000)$ & 47.199 & 4.323 \\
Percentage of students in lunch program & 0.431 & 0.258 \\
Median teacher experience (years) & 7.553 & 3.260 \\
Teacher experience per pupil (years) & 0.520 & 0.147 \\
Unrestricted revenue per pupil $(\$ 1,000)$ & 4.629 & 1.083 \\
Restricted revenue per pupil $(\$ 1,000)$ & 1.638 & 0.613 \\
Elementary school district $(0-1$ variable) & 0.502 & 0.500 \\
High school district $(0-1$ variable) & 0.101 & 0.302 \\
\hline
\end{tabular}

Our twenty-year experience premium corresponds to the path a typical teacher would take over their career as they move southeast through their salary schedule. This premium grows both because of work experience and education. In that sense, our premium has two components. Holding education constant at a BA plus 60 units, teachers who move from step 1 to step 21 gain an average of \$18,666 over twenty years, or about $\$ 933$ per year. On the other hand, teachers who move from the first to the last column while remaining at step 11 increase their salary by an average of $\$ 6,533$. In our empirical analysis, we estimate the effect of our regressors on the two components of the experience premium as well as on the premium itself.

The independent variables in our regression can be partitioned into three categories - variables hypothesized to affect the power of the union in collective bargaining, variables hypothesized to affect the marginal value of the experience premium, and variables determining the district's budget constraint. Table 2 provides summary statistics for these variables. 
Our theory predicts that the power of the teachers' union is related to two variables. The first is the number of eligible voters in the school district, which in our theory determines the cost of campaigning. To construct this variable, we use data from the 2000 Census. Ideally, eligible voters would be the number of citizens in the district who are eighteen years or older, however, the Census does not provide this data at the school district level. We approximate this ideal measure using the product of the number of people in the district who are eighteen years or older and the percentage of U.S. citizens in the district. On average, California school districts had about 33,000 eligible voters.

Although our measure of eligible voters is simple to determine, it raises two issues. The first is that some school districts elect board members by area, which may increase the power of homeowners. We have investigated this frequency of area elections using data in the California Elections Archive. ${ }^{2}$ Among school board elections in 1999 and 2000 that are recorded in the Archive, 15 percent held area elections. Large districts were more likely to hold these elections than small districts. Of districts with fewer than 20,000 students, only 14 percent held area elections. Of districts with more than 20,000 students, 23 percent held these elections. Because the Archive does not include data on half of the districts in our sample, we cannot use it to construct a variable indicating whether a district held area elections. However, the tendency of large districts to hold area elections suggests that our measure of eligible voters may overstate the advantage of unions in large districts.

The second issue raised by our measure of voters is the timing of elections. As the Hess survey shows, voter turnout is higher when school board elections are held at the same time as other elections than when they are held at special times. As a consequence, effective campaign costs may be lower in these special elections. Special elections are relatively rare for California school districts, however. Among elections in the Archive for 1999 and 2000, 57 percent were held during the November 2000 general elections. Another 38 percent were held during the November 1999 elections when several important statewide initiatives were on the ballot and when many cities held mayoral and council

\footnotetext{
${ }^{2}$ The Archive is maintained by the Institute of Social Research at California State University, Sacramento.
} 
elections. Only 5 percent of elections were held at special times, and large districts were no more likely than small districts to hold these special elections.

Our model also predicts that, all else equal, the political power of the teachers' union is increasing in the ratio of teachers to eligible voters. Including this ratio in our regression raises an endogeneity issue, however. The ratio of teachers to eligible voters is the product of the teacher-pupil ratio and the ratio of pupils to eligible voters. In addition, the teacher-pupil ratio is linked to a district's experience premium through its budget constraint. A district with an experience premium higher than predicted by our model must compensate in other ways to satisfy its budget constraint. One possible compensation is a lower teacher-pupil ratio, and thus the teacher-pupil ratio could be correlated with the error term in the regression for the experience premium. To avoid this potential problem, we use the ratio of students to eligible voters as a proxy for the ratio of teachers to eligible voters. Conceptually, if two districts of the same size and with the same teacher-pupil ratio had different numbers of students, the one with more students would also have more teachers, a lower cost of contributions, and thus more contributions. The number of students comes from the California Basic Educational Data System (CBEDS) maintained by the California Department of Education. On average, districts had one student for every four eligible voters.

A third variable that seems likely to affect the political power of the teachers' union is homeownership. Although our theory does not predict the effect of homeownership on union power, we include in our regression the percentage of households in a school district that owned their homes. On average, 65 percent of households owned their homes. Data on this variable come from the 2000 Census.

Three variables are hypothesized to affect the marginal value of the experience premium. The first is the salary that a teacher could earn in alternative employment. Because school districts must compete with other employers to attract employees, districts in regions with higher non-teacher salaries would typically offer higher teacher salaries as well. As a measure of the alternative salary teachers could earn, we use a regional salary based on the Occupational Employment Statistics (OES) survey conducted by the California Employment Development Department. This survey collected employment levels and 
mean annual salaries in more than 700 occupations for a sample of 113,000 California establishments between 1999 and 2001. The OES reports data for 25 Metropolitan Statistical Areas (MSA) and 5 additional regions that cover the 24 counties not in a MSA. On average, each region contained 14 districts within its boundaries. Eleven regions had between two and six districts. The Los Angeles-Long Beach region contained 71 school districts. For each region, we calculate the regional salary as the weighted average of mean salaries in non-teaching occupations that require a bachelor's degree. The weight for each occupation's mean salary is the proportion of workers statewide in that occupation. On average, districts faced a regional salary of $\$ 47,199$.

Secondly, a district's competitive position in the market for new teachers might also be related to the characteristics of its students. Academic achievement is strongly related to family income, and a school in a low-income neighborhood is a challenging teaching assignment. Districts with many such schools may find it necessary to offer higher salaries to be competitive. Thus, we control for the percentage of a district's students who participated in the National School Lunch Program. To participate, the income of a student's family must be less than 185 percent of the poverty level. Data on this variable are from CBEDS.

The third variable hypothesized to affect the marginal value of the experience premium is the median experience of teachers. In our model, the union is represented by the teacher with the median experience, and more senior teachers place a higher value on the experience premium. District data on teacher experience come from CBEDS. In 1999-2000, the median experience level of teachers averaged 7.6 years across districts.

The last group of variables reflects the district's budget constraint. The first variable is the total years of teacher experience per pupil, which is the price of the experience premium in the district's budget constraint. Data on student enrollment come from CBEDS. Experience per pupil is closely related to median experience with a correlation coefficient of 0.7 .

A school district's budget constraint is also determined by its revenue. We focus on the general fund, which includes all revenue used to finance instructional activities. The general fund excludes 
capital, deferred maintenance, and cafeteria funds, which together account for less than 20 percent of total revenue. In 1999-2000, school districts averaged $\$ 6,268$ of general fund revenue per pupil. A school district's general fund receives two main types of revenue: unrestricted and restricted. Unrestricted revenue can be spent on any legitimate expense and comprised 74 percent of all general fund revenue. Restricted revenue, such as state and federal categorical programs, provided the remaining 26 percent. These funds generally target certain student populations, such as special education students, or certain functions, such as pupil transportation. Each type of revenue, measured in per-pupil terms, is an independent variable in our model. These data come from the School District Revenue and Expenditure Report (J-200) maintained by the California Department of Education.

Our regression includes two more independent variables that capture an important institutional distinction among California school districts. Approximately 70 percent of California's public school students are enrolled in unified school districts, which include all grades from kindergarten through twelfth grade. Unified districts account for about half of the districts in the state. The remainder are either elementary school districts or high school districts. An elementary district generally includes kindergarten through eighth grade, and a high school district generally includes ninth through twelfth grades. Because costs in these three types of districts may differ, the relationship between revenue and our dependent variable may also differ among them. Accordingly, we include two dummy variables indicating whether a district is either an elementary school district or a high school district.

In estimating our model, variables are measured in natural logarithms so that coefficients are elasticities. The only exceptions are the dichotomous variables and variables measured in percentages, specifically, the dichotomous variables for elementary and high school districts, the ratio of students to eligible voters, and the percentage of homeowners. Our econometric model accounts for the fact that regional salary has the same value for all districts in the same region. As Moulton (1990) shows, correlation among the error terms of observations in a group, such as a region, may bias the standard errors of variables that are constant across observations in a group. To correct for this bias, we assume 
Table 3

Coefficient Estimates

Dependent Variable: Experience Premium

\begin{tabular}{lc}
\hline Eligible voters & $0.041^{* *}$ \\
& $(0.008)$ \\
Students per eligible voter & $0.133^{* *}$ \\
& $(0.057)$ \\
Percentage of homeowners & $-0.140^{*}$ \\
& $(0.077)^{*}$ \\
Regional salary & $0.432^{* *}$ \\
& $(0.102)$ \\
Percentage of students in lunch program & -0.036 \\
& $(0.046)$ \\
Median teacher experience & $0.054^{* *}$ \\
& $(0.026)$ \\
Teacher experience per pupil & -0.079 \\
& $(0.056)$ \\
Unrestricted revenue per pupil & $0.131^{* *}$ \\
Restricted revenue per pupil & $(0.059)$ \\
Elementary school district dummy & -0.036 \\
High school district dummy & $(0.039)$ \\
Constant & $0.0699^{* *}$ \\
\hline R-squared & $(0.024)$ \\
\hline
\end{tabular}

Notes: ${ }^{* *}$ denotes significance at the five percent level; ${ }^{*}$ denotes significance at the 10 percent level. Standard errors are in the parentheses. There are 771 observations in the regression. All variables are measured in natural logarithms except ratios and dichotomous variables.

that the error term has a region-specific component and compute standard errors that account for this error specification.

Table 3 presents the coefficients and standard errors for the regression of the twenty-year experience premium on our independent variables. Our main hypothesis is that the experience premium increases with number of eligible voters in the district. Table 3 shows that the data corroborate this hypothesis. The coefficient on eligible voters is positive and more than five times its standard error. Our 
interpretation is that larger districts have more powerful unions and that these unions use their power to increase the experience premium. Although the effect on the experience premium is only one indicator of the union's overall power, it is informative to examine the magnitude of the coefficient. The coefficient implies that the ten largest districts in our sample, which average 320,000 eligible voters (excluding Los Angeles with over 2.3 million eligible voters), would have an experience premium about ten percent higher than the average district in our sample with 33,000 eligible voters. If the average district had the average premium of $\$ 1,173$, the larger districts would have a premium of $\$ 1,287$. For a teacher with twenty years of experience, the predicted difference in annual salary would be $\$ 2,284$.

To check whether our model effectively captures the relationship between the experience premium and the size of the school district, we plotted the residuals of the regression against the log of eligible voters. The plot suggests that our measure of district size does not exclude any important nonlinear effects.

Based on our theoretical model, we also hypothesize that the ratio of students to eligible voters is positively related to union power. As predicted, the coefficient on this ratio is positive and significant. Though homeownership is an important part of our public choice theory, our model does not have a clear prediction about how homeownership affects union power. In our regression, the percentage of homeowners is negatively related to union power but only marginally significant.

The experience premium has two components: the direct effect of experience on salary holding education constant and the indirect effect of experience on education as teachers acquire more educational units throughout their career. We have estimated the effect of our set of regressors on each of these two components. For the first component, we take the annual gain in salary moving from step 1 to step 21 holding education constant at a BA plus 60 units. For the second, we take gains in salary due strictly from moving from the lowest to the highest column in the district holding experience constant at step 11. For the experience component, the coefficient on eligible voters is almost twice as large as the coefficient for the premium itself, and the coefficient on the student-voter ratio is about 50 percent larger. The coefficients on these two measures of union power are also statistically significant. In contrast, there is 
no significant relationship between our measures of union power and the education component of the premium. This finding that union power is more closely related to the experience component of the premium than to the education component reinforces the idea that the premium is a rent to senior teachers rather than a reward for productivity.

Table 3 shows that school districts react to higher regional salaries by increasing their experience premium. The table also indicates that the experience premium is positively related to the median years of teacher experience, which reflects the increased marginal value of the premium to unions with more experienced members.

The positive coefficient on unrestricted revenue suggests that the experience premium is a normal good. This normality implies that the experience premium should decrease in response to an increase in its price. Consistent with this expectation, the estimated coefficient on the total years of teacher experience per pupil, the price of the premium, is negative although not statistically significant. Taken together with the positive effect of median teacher experience, however, equal percentage increases in the experience variables would largely offset each other.

As we noted in the previous section, a positive relationship between district size and the experience premium might be explained by higher turnover in large districts than in small districts. As we also noted, however, this alternative explanation is not consistent with observed turnover behavior. New teachers are less likely to leave large districts than small districts. The relationship between the base salary and district size is also evidence against this alternative explanation. If large districts have higher turnover than small districts, they would offer higher experience premiums and lower base salaries than small districts. To check this later implication, we estimated the base salary in our sample of districts as a function of the eleven independent variables listed in Table 2. In that regression, base salary is positively and significantly related to district size, measured by the number of eligible voters. That is, large districts offer both higher base salaries and higher experience premiums than small districts offer. We believe that this result is more consistent with our theory that teachers' unions are more powerful in large districts than the hypothesis that large districts face higher turnover than small districts. 
The finding that both the base salary and the experience premium are higher in large districts points to another possibility. Large districts tend to have higher percentages of low-income students, who present more challenging teaching assignments. Perhaps the higher salaries we observe merely reflect a compensating differential for those assignments. This interpretation is not consistent with our findings, however, because the experience premium is not significantly related to the percentage of a district's students enrolled in the National School Lunch Program.

In sum, the results from the baseline regression are consistent with our main theoretical prediction about district size and the experience premium and inconsistent with two other explanations of that prediction. To test the robustness of our results, we explore three alternate specifications. First, we examine whether economies of scale explain the effects of district size. Second, we account for potential endogeneity in the experience regressors using instrumental variables. Third, we expand our model to include additional factors hypothesized to affect union power.

\section{Economies of Scale}

If districts experience economies of scale due to the fixed cost of administration, an increase in district size would have the same effect as an increase in revenue. Larger districts would choose more of all normal goods, including the experience premium. This alternative explanation also implies that larger districts should have higher teacher-pupil ratios, assuming that ratio is a normal good. To examine this implication, we estimated a model of the teacher-pupil ratio as a function of the same independent variables in our model of the experience premium. We found that an increase in revenue increases the teacher-pupil ratio, confirming that teachers are a normal good. However, an increase in district size decreases the teacher-pupil ratio. Increases in the experience premium due to increases in district size come at the expense of the teacher-pupil ratio, not in companion with increases in that ratio as would be expected if school districts experienced economies of scale. Economies of scale at the district level do not seem to explain the relationship between school district size and the experience premium. 
A related point centers on economies of scale at the school level. Suppose there is an efficient class size at which the marginal benefit of reducing size equals its marginal cost. In rural areas where population density is low, it may be difficult to attain large enough classes without transporting students long distances to school. As Kenny (1982) argues, such schools have to balance the economies of larger classes against transportation costs, resulting in class sizes lower than the efficient size and fewer resources available for other purposes. In districts with many such schools, teacher-pupil ratios would tend to be higher than average and salaries and other expenditures would tend to be lower than average. Because districts in rural areas also tend to be small in size, the experience premium and the base salary would be positively related to district size and the teacher-pupil ratio would be negatively related to size.

To determine whether school economies of scale may be the cause of the observed relationship between the experience premium and district size, we re-estimate our baseline model, adding a control for the population density of the school district. A district's density is defined as the population residing within its boundaries divided by the square meters of land area within those boundaries. These data are available from the 2000 U.S. Census and enter our model in log form. The second column of Table A.1 in the Appendix shows the results from adding the population density to our model. For comparison, the first column shows the baseline estimates from Table 3.

The most important result is that the coefficient on eligible voters is still positive and significant in the model with density. Furthermore, that coefficient is only only slightly smaller in magnitude than in its corresponding baseline regression. The coefficient on population density, however, is not significant, indicating that school-level economies of scale do not appear to explain the relationship between the experience premium and school district size.

\section{Endogeneity of Teacher Experience}

Our empirical model assumes that the experience premium is a function of the two experience variables in our model, median experience and teacher experience per pupil. However, these two variables may also be functions of the experience premium. Districts with a high experience premium 
may induce teachers to stay in the district longer, thus increasing median teacher experience and experience per pupil in those districts. The possibility of a simultaneous relationship between the experience premium and the two experience measures means that the estimated coefficients could be biased. If districts with large experience premiums have less teacher turnover, they will also tend to have more experienced teachers. As a consequence, our two experience measures may be correlated with the error term in our regression. Any such correlation would bias upward our estimates of the coefficients on those two measures. In addition, this type of correlation would tend to bias downward the coefficient on eligible voters. This downward bias could result because, if large districts tend to have higher premiums, they would also tend to have more experienced teachers. District size and teacher experience would therefore be correlated, raising the possibility that the effect of size on the premium may be partly attributed to the experience variables.

To remove the bias, we need variables that are related to the experience measures but not determined by the experience premium. We propose that enrollment growth rates in previous years meet both conditions. Past enrollment growth rates affect the number of teachers hired in previous years and thus teacher experience in the current year. However, a district's current collective bargaining outcomes are unlikely to affect a district's past enrollment growth rates. Accordingly, we re-estimate our regressions using two-stage least squares (TSLS), with past growth rates as instruments for median teacher experience and teacher experience per pupil.

We use six five-year growth rates: 1970 to 1975, 1975 to 1980, and so on through 1995 to 2000 . The more distant growth rates are unlikely to be determined by the current experience premium, but they may also be weaker predictors of the teacher experience variables than are the more recent growth rates. The more recent growth rates, however, risk being correlated with the error term if teachers who expect to stay in teaching longer are attracted to districts expected to offer a higher premium. Under the maintained assumption that the earliest two growth rates are exogenous, we can test whether the four most recent growth rates are also exogenous using Hansen's J-statistic (see Hansen (1978) and Baum, Schaffer, 
Stillman, (2003)). This common test for over-identifying restrictions indicates that these four extra instruments are exogenous, and thus we use all six growth rates as instruments in our TSLS estimates.

The third column of Table A.1 shows those estimates. Our main theoretical prediction is supported by the TSLS estimates. The coefficient on eligible voters is still positive, significant, and similar in magnitude to the previous model. The experience variables, however, are no longer significant due to the lower precision of the TSLS estimator.

The insignificance of the experience variables could arise from weak instruments, i.e., the enrollment growth variables are weakly correlated with the experience variables. In the first stage regressions, the F-statistics for the joint significance of the six growth rates are 29.24 for median teacher experience and 18.32 for teacher experience per pupil. However, a test that accounts for the intercorrelations of the instruments and the two experience variables indicates that the growth variables do not separately identify the coefficients of the two experience variables. ${ }^{3}$ The intuition behind this result is that the instruments succeed in explaining each of the experience variables, but they are not strong enough to identify the two separate effects of the experience measures. Thus, our TSLS estimates may not have completely removed the downward bias in the coefficient on eligible voters, meaning that the effect of eligible voters on the experience premium may exceed our estimate of that effect.

\section{Additional Factors Hypothesized to Affect Union Power}

The public choice model underlying our regression assumes that political representation is imperfect, thus creating the possibility for interest groups to influence school board elections. Our model focuses on a few specific factors relevant to the influence of a teachers' union. However, other factors may also be relevant. This subsection discusses a number of these factors and reports the results of a

\footnotetext{
${ }^{3}$ See Stock and Yogo (2003) for a description of an appropriate test for weak instruments with multiple endogeneous variables. The test is based on the minimal eigenvalue of the matrix analog of the F-statistic from the TSLS first stage regression.
} 
regression in which the previous model is expanded to include these other factors. We are particularly concerned with factors that may be correlated with our measures of union power.

The first factor is civic engagement. In communities in which residents are actively engaged in civic affairs, interest groups will be less influential. Putnam (1995) summarizes the empirical research on civic engagement, concluding that education and income are important predictors of engagement. This conclusion is particularly significant for our results because both education and income are correlated with homeownership. As a consequence, in our baseline model, homeownership may be acting as a proxy for civic engagement rather than the role posited for it in our public choice theory. To examine this possibility, we include measures of both education and income in our expanded model. Specifically, we use 2000 Census data to include median family income in the school district and the percentage of the district's population with a bachelor's degree.

Putnam views civic engagement as nearly synonymous with the concept of social capital as described by Coleman (1990). Putnam interprets this concept to mean the "features of social lifenetworks, norms, and trust— that enable participants to act together more effectively to pursue shared objectives." These features of social life may be more difficult to establish in racially and ethnically heterogeneous communities, and heterogeneity is likely to be correlated with school district size. Accordingly, in our baseline model, district size may be acting as a proxy for the potentially more important factor of racial and ethnic heterogeneity. To examine this possibility, our expanded model includes a measure of homogeneity. The measure is a Herfindahl index based on eight race and ethnicity classifications in the 2000 Census. To calculate a district's index, we first calculate each classification's share of district population, square those shares, and then sum them across all classifications. For a district with just one racial or ethnic group, the resulting index is unity. At the other extreme, for a district in which each group is equally represented, the index is $1 / 8$.

Another factor that may affect the influence of a teachers' union is the political ideology of a school district's voters. Babcock and Engberg (1999) hypothesize that, given the historic ties between the Democratic Party and organized labor, a community's support for its teachers' union is related to the 
percentage of its voters that register as Democrats. To test that hypothesis, we include the percentage of voters in a school district's county that are registered as Democrats. These data come from the California Secretary of State's office.

The competitiveness of the market for public school quality may also affect union power. In areas with few school districts from which to choose, and therefore little competition for quality, the relationship between school quality and house values may be relatively weak. This effect diminishes the incentive of homeowners to closely monitor the quality of their local public schools. Hoxby (1996) uses a Herfindahl index to measure the degree of public school competition. Following that example, we also include a Herfindahl index, calculated on a county basis. To determine a county's index, we first calculate each district's share of its county's school enrollment, square those shares, and then sum them across all districts in the county. CBEDS provides data on district and county enrollment.

We add these five additional variables to the previous regression and continue to use two-stage least squares. Median income enters in log form, but the percentages and Herfindahl indices enter in levels. The results are displayed in the final column of Table A.1. Adding these five variables has little effect on the coefficients of interest.

Most important, the coefficient on eligible voters is still positive and significant, as is the coefficient on students per eligible voter. Furthermore, none of five additional variables in this regression are significant at a reasonable level, nor are they jointly significant. The coefficient on regional salary is no longer significant. This result is not surprising, because median income and regional salary are positively correlated with a coefficient of 0.7 . 


\section{Conclusions}

The economics of a school district are significantly affected by the power of its teachers' union in collective bargaining. We hypothesize that this power is positively related to the number of eligible voters in a district, a hypothesis derived from a public goods theory of school board politics. As an empirical indicator of a union's success in collective bargaining, we use the experience premium in the salary schedule for teachers. We find that this premium is positively related to the number of eligible voters, a finding consistent with our hypothesis.

By focusing on the experience premium, we do not intend to imply that this is the only outcome of interest to union members. Work rules, class sizes, and benefits are other important issues. We focused on the experience premium because we believe it is the clearest indicator of union success in diverting district resources to provide rents for union members. Unions that are successful in negotiating high experience premiums are also likely to be successful in negotiating other terms and conditions favorable to union members. Relative to the experience premium, these other terms and conditions may be more important to union members and more costly to the district.

Our theory of district size and union power is relevant to two other important findings in the economics of public schools. First, Hoxby (2000) finds that public school productivity is higher in metropolitan areas in which families have a wide range of school districts from which to choose. She hypothesizes that families in areas with many districts will be better able to determine the effectiveness of districts in producing school quality and that consequently districts in these areas will be less able to divert rent to schooling producers. Our theory suggests another avenue through which choice among school districts may affect school productivity. Everything else equal, an area with more districts will also have smaller districts on average. Smaller districts have less powerful teachers' unions and thus divert fewer resources to producing rent for union members.

Second, our theory also suggests a different interpretation of the findings of Kenny and Schmidt (1994), who seek to explain the decrease in the number of school districts in the United States between 1950 and 1980. They find that the decrease in the number of school districts in a state is related to the 
increase in the number of its teachers that belong to the National Education Association teachers' union. In explaining this result, they argue that there is a fixed cost to organizing a union and thus organization will be less costly overall if unions have fewer districts to contend with. Teachers' unions thus lobby for policies to consolidate districts, an effort that will be more successful if many teachers are union members. Reinforcing this factor, teachers' unions are more likely to organize districts in states in which districts tend to be large. In contrast to this focus on the fixed cost of organizing, our theory points to the benefits of organizing a union. If union power increases with district size, as our theory predicts, the benefits of organizing are greater in large school districts, giving unions an incentive to lobby for district consolidation and making union membership more prevalent in states with large districts. 


\section{References}

Babcock, Linda, and John Engberg, "Bargaining Unit Composition and the Returns to Education and Tenure," Industrial and Labor Relations Review, Volume 52, Number 2, January 1999, pages 163178.

Ballou, Dale, and Michael Podgursky, "Returns to Seniority Among Public School Teachers," Journal of Human Resources, Volume 37, Number 4, Fall 2002, pages 892-912.

Baugh, William H., and Joe A. Stone, "Teachers, Unions, and Wages in the 1970s: Unionism Now Pays," Industrial and Labor Relations Review, Volume 35, Issue 3, April 1982, pages 368-376.

Baum, Christopher F., Mark E. Schaffer, and Steven Stillman, "Instrumental Variables and GMM: Estimation and Testing,” Working Paper No. 545, Boston College, 2003.

Bergstrom, Theodore C., Lawrence Blume, and Hal Varian, "On the Private Provision of Public Goods," Journal of Public Economics, Volume 29, Number 1, 1986, pages 25-49.

Brunner, Eric, and Jon Sonstelie, "School Finance Reform and Voluntary Fiscal Federalism," Journal of Public Economics, Volume 87, 2003, pages 2157-2185.

Coleman, James, Foundations of Social Theory, Harvard University Press: Cambridge, Mass, 1990.

Courant, Paul N., Edward Gramlich, and Daniel L. Rubinfeld, "Public Employee Market Power and the Level of Government Spending," American Economic Review ,Volume 69, Number 5, December 1979, pages 806-817.

Eberts, Randall W., and Joe A. Stone, "Teachers' Unions and the Productivity of Public Schools," Industrial and Labor Relations Review, Volume 40, 1987, pages 355-63.

Edlefson, Lee E., "The Comparative Statics of Hedonic Price Functions and Other Nonlinear Constraints," Econometrica, Volume 49, Number 6, November 1981, pages 1501-1520.

Farber, Henry S., "Individual Preferences and Union Wage Determination: The Case of the United Mine Workers," Journal of Political Economy, Volume 86, Number 5, October 1978, pages 923-942.

Farber, Henry S., "The Analysis of Union Behavior," in Handbook of Labor Economics, Volume 2, edited by Orley C. Ashenfelter and Richard Layard, 1986.

Fischel, William A., The Homevoter Hypothesis, Harvard University Press: Cambridge, Mass., 2001.

Freeman, R. B., "Individual Mobility and Union Voice in the Labor Market," American Economic Review, Volume 66, Number 2, May 1976, pages 361-368.

Freeman, Richard B., "Unionism Comes to the Public Sector," Journal of Economic Literature, Volume 24, March 1986, pages 41-86.

Hansen, L., "Large Sample Properties of Generalized Method of Moments Estimators," Econometrica Volume 50, Number 3, 1978, pages 1029-1054. 
Hess, Frederick M., "School Boards at the Dawn of the $21^{\text {st }}$ Century: Conditions and Challenges of District Governance," National School Boards Association, 2002.

Hoxby, Caroline Minter, "How Teachers' Unions Affect Education Production," Quarterly Journal of Economics, Volume 111, 1996, pages 671-718.

Hoxby, Caroline M., "Does Competition Among Public Schools Benefit Students and Taxpayers?," American Economic Review, Volume 90, Number 5, 2000, pages 1209-1238.

Kenny, Lawrence W., "Economies of Scale in Schooling," Economics of Education Review, Volume 2, Number 1, 1982, pages 1-24.

Kenny, Lawrence W., and Amy B. Schmidt, "The Decline in the Number of School Districts in the U.S.: 1950-1980,” Public Choice, Volume 79, 1994, pages 1-18.

Kleiner, Morris M., and Daniel L. Petree, "Unionism and Licensing of Public School Teachers: Impact on Wages and Educational Output," in When Public Sector Workers Unionize, edited by Richard B. Freeman and Casey Ichniowski, University of Chicago Press, Chicago, 1988.

Kuhn, Peter, “A Nonuniform Pricing Model of Union Wages and Employment," Journal of Political Economy, Volume 96, Number 3, June 1988, pages 473-508.

Lazear, Edward P., Personnel Economics, The MIT Press: Cambridge, Mass., 1995.

Lankford, Hamilton, and James Wyckoff, "The Changing Structure of Teacher Compensation, 1970-94," Economics of Education Review, Volume 16, Number 4, 1997, pages 371-384.

Ledyard, John O., "Public Goods: A Survey of Experimental Research," in The Handbook of Experimental Research, edited by John H. Kagel and Alvin E. Roth, Princeton University Press: Princeton, NJ, 1995.

Loeb, Susanna, and Marianne E. Page, "Examining the Link Between Teacher Wages and Student Outcomes: The Importance of Alternative Labor Market Opportunities and Non-Pecuniary Variation," Review of Economics and Statistics, Volume 82, Number 3, 2000, pages 393-408.

Moe, Terry M., “Teachers Unions and School Board Elections,” Stanford University, October 2003.

Moulton, Brent R., "An Illustration of a Pitfall in Estimating the Effects of Aggregate Variables on Micro Units," The Review of Economics and Statistics, Volume 72, Issue 2, May 1990, pages 334-38.

O'Brien, Kevin M., "Compensation, Employment, and the Political Activity of Public Employee Unions," Journal of Labor Research, Volume 13, Number 1, Winter 1992, pages 189-203.

O'Brien, Kevin M., "The Impact of Union Political Activities on Public-Sector Pay, Employment, and Budgets," Industrial Relations, Volume 33, Number 3, July 1994, pages 322-345.

O'Brien, Kevin M., "The Effect of Political Activity by Police Unions on Nonwage Bargaining Outcomes," Journal of Collective Negotiations in the Public Sector, Volume 25, Number 2, 1996, pages 99-116. 
Oliver, J. Eric, "City Size and Civic Involvement in Metropolitan America," American Political Science Review, Volume 94, Number 2, June 2000, pages 361-373.

Putnam, Robert D., "Tuning In, Tuning Out: The Strange Disappearance of Social Capital in America," PS: Political Science \& Politics, Volume 28, Number 4, December 1995, pages 655-683.

Reed, Deborah, Kim Rueben, and Elisa Barbour, "Recruitment and Retention of New Teachers in California," Public Policy Institute of California, December 2003.

Stock, James H. and Motohiro Yogo, (2003), “Testing for Weak Instruments in Linear IV Regression, Department of Economics", Harvard University, unpublished manuscript.

Stone, Joe A., "Collective Bargaining and Public Schools," in Conflicting Missions? Teacher Unions and Educational Reform, Tom Loveless, editor, Brookings Institution Press, Washington, D.C., 2002. 


\section{Appendix}

\section{The Collective Bargaining Problem}

The collective bargaining problem is represented as a constrained maximization problem. The Lagrangean function of that problem is

$$
U+\mu(y-x-b n-E \pi),
$$

and the first order conditions are

$$
\begin{aligned}
& U_{x}-\mu=0, \\
& U_{n}-\mu b=0, \\
& U_{b}-\mu n=0, \\
& U_{\pi}-\mu E=0, \text { and } \\
& y-x-b n-E \pi=0 .
\end{aligned}
$$

Totally differentiating the first order conditions yields the matrix equation

$$
A\left[\begin{array}{l}
d x \\
d n \\
d b \\
d \pi \\
d \mu
\end{array}\right]+\left[\begin{array}{ccccc}
0 & 0 & U_{x w} & U_{x \lambda} & 0 \\
0 & 0 & U_{n w} & U_{n \lambda} & 0 \\
0 & 0 & U_{b w} & U_{b \lambda} & 0 \\
0 & (1+\lambda) & U_{\pi w} & U_{\pi \lambda} & -\mu \\
1 & 0 & 0 & 0 & -\pi
\end{array}\right]\left[\begin{array}{c}
d y \\
d \tilde{e} \\
d w \\
d \lambda \\
d E
\end{array}\right]=0 .
$$

Following Edlefson (1981),

$$
A^{-1}=\left[\begin{array}{cc}
N & -\alpha \\
-\alpha^{\prime} & \delta
\end{array}\right],
$$

where the matrix $N$ is symmetric and negative semi-definite, and

$$
N=\left[\begin{array}{llll}
N_{x x} & N_{x n} & N_{x b} & N_{x \pi} \\
N_{n x} & N_{n n} & N_{n b} & N_{n \pi} \\
N_{b x} & N_{b n} & N_{b b} & N_{b \pi} \\
N_{\pi x} & N_{\pi n} & N_{\pi b} & N_{\pi \pi}
\end{array}\right], \text { and } \alpha=\left[\begin{array}{c}
\alpha_{x} \\
\alpha_{n} \\
\alpha_{b} \\
\alpha_{\pi}
\end{array}\right] .
$$


Proof that $\frac{\partial \pi}{\partial \lambda} \geq 0$

The matrix $N$ is proportional to the Hicksian substitution effects. In particular, let $x^{*}, n^{*}, q^{*}$, and $\pi *$ be compensated demands. Then,

$$
\begin{aligned}
& \frac{\partial x^{*}}{\partial E}=\mu N_{x \pi}, \\
& \frac{\partial n^{*}}{\partial E}=\mu N_{n \pi}, \\
& \frac{\partial b^{*}}{\partial E}=\mu N_{b \pi}, \text { and } \\
& \frac{\partial \pi *}{\partial E}=\mu N_{\pi \pi} .
\end{aligned}
$$

From (A1),

$$
\frac{\partial \pi}{\partial \lambda}=-\left(N_{\pi x} U_{x \lambda}+N_{\pi n} U_{n \lambda}+N_{\pi b} U_{b \lambda}+N_{\pi \pi} U_{\pi \lambda}\right)
$$

Because $N$ is symmetric and $U=(1+\lambda) U^{t}+(1-\lambda) U^{h}$, this expression can be written as

$$
\frac{\partial \pi}{\partial \lambda}=-\mu^{-1}\left[\left(U_{x}^{t}-U_{x}^{h}\right) \frac{\partial x^{*}}{\partial E}+\left(U_{n}^{t}-U_{n}^{h}\right) \frac{\partial n^{*}}{\partial E}+\left(U_{b}^{t}-U_{b}^{h}\right) \frac{\partial b^{*}}{\partial E}+\left(U_{\pi}^{t}-U_{\pi}^{h}\right) \frac{\partial \pi *}{\partial E}\right]
$$

This expression can be rewritten as

$$
\frac{\partial \pi}{\partial \lambda}=\mu^{-1}\left[\frac{\partial U^{h} *}{\partial E}-\frac{\partial U^{t} *}{\partial E}\right]
$$

where $\frac{\partial U^{t} *}{\partial E}$ is the effect on $U^{t}$ of a change in $E$, with income compensated to hold $(1+\lambda) U^{t}+(1-\lambda) U^{h}$ constant. $\frac{\partial U^{h} *}{\partial E}$ is similarly defined. Because $U$ is held constant, there are two possibilities: either $\frac{\partial U^{t} *}{\partial E} \leq 0$ and $\frac{\partial U^{h} *}{\partial E} \geq 0$ or $\frac{\partial U^{t} *}{\partial E}>0$ and $\frac{\partial U^{h} *}{\partial E}<0$

Suppose the second possibility is true. Then, 


$$
\left(\frac{U_{x}^{t}}{U_{\pi}^{t}}\right) \frac{\partial x^{*}}{\partial E}+\left(\frac{U_{n}^{t}}{U_{\pi}^{t}}\right) \frac{\partial n^{*}}{\partial E}+\left(\frac{U_{b}^{t}}{U_{\pi}^{t}}\right) \frac{\partial b^{*}}{\partial E}+\frac{\partial \pi^{*}}{\partial E}>0
$$

and

$$
\left(\frac{U_{x}^{h}}{U_{\pi}^{h}}\right) \frac{\partial x^{*}}{\partial E}+\left(\frac{U_{n}^{h}}{U_{\pi}^{h}}\right) \frac{\partial n^{*}}{\partial E}+\left(\frac{U_{b}^{h}}{U_{\pi}^{h}}\right) \frac{\partial b^{*}}{\partial E}+\frac{\partial \pi^{*}}{\partial E}<0 .
$$

Combining the above two equations,

$$
\left(\frac{U_{x}^{t}}{U_{\pi}^{t}}-\frac{U_{x}^{h}}{U_{\pi}^{h}}\right) \frac{\partial x^{*}}{\partial E}+\left(\frac{U_{n}^{t}}{U_{\pi}^{t}}-\frac{U_{n}^{h}}{U_{\pi}^{h}}\right) \frac{\partial n^{*}}{\partial E}+\left(\frac{U_{b}^{t}}{U_{\pi}^{t}}-\frac{U_{b}^{h}}{U_{\pi}^{h}}\right) \frac{\partial b^{*}}{\partial E}>0 .
$$

On the other hand, if $x, n$, and $b$ are substitutes for $\pi$ and if the union values $\pi$ relatively more than homeowners value it,

$$
\left(\frac{U_{x}^{t}}{U_{\pi}^{t}}-\frac{U_{x}^{h}}{U_{\pi}^{h}}\right) \frac{\partial x^{*}}{\partial E}+\left(\frac{U_{n}^{t}}{U_{\pi}^{t}}-\frac{U_{n}^{h}}{U_{\pi}^{h}}\right) \frac{\partial n^{*}}{\partial E}+\left(\frac{U_{b}^{t}}{U_{\pi}^{t}}-\frac{U_{b}^{h}}{U_{\pi}^{h}}\right) \frac{\partial b^{*}}{\partial E}<0 .
$$

As a consequence of this contradiction, the first possibility must be true, which implies that $\frac{\partial \pi}{\partial \lambda} \geq 0$.

Proof that $\frac{\partial \pi}{\partial E} \leq 0$

From (A1),

$$
\frac{\partial \pi}{\partial E}=\mu N_{\pi \pi}-\pi \alpha_{\pi}
$$

Because $\frac{\partial \pi}{\partial y}=\alpha_{\pi}$, this expression can be written as

$$
\frac{\partial \pi}{\partial E}=\mu N_{\pi \pi}-\pi \frac{\partial \pi}{\partial y}
$$


The term $\mu N_{\pi \pi}$ is the Hicksian own-price substitution effect and thus the equation above is the standard

Slutsky equation. Because $N$ is negative semi-definite, $N_{\pi \pi} \leq 0$. Also, $\mu \geq 0$. Thus, if $\pi$ is a normal good, $\frac{\partial \pi}{\partial E} \leq 0$

Proof that $\frac{\partial \pi}{\partial \widetilde{e}} \geq 0$

From (A1),

$$
\frac{\partial \pi}{\partial \tilde{e}}=-(1+\lambda) N_{\pi \pi} .
$$

Because $N$ is negative semi-definite, $\frac{\partial \pi}{\partial \widetilde{e}} \geq 0$.

\section{Nash Equilibrium}

The Nash equilibrium is defined by

$$
\begin{aligned}
& c^{t}=R^{t}\left(c^{h}, \theta, \tau\right) \\
& c^{h}=R^{h}\left(c^{t}, \theta, Z\right) .
\end{aligned}
$$

Totally differentiating these two equations yields

$$
\left[\begin{array}{cc}
1 & -\frac{\partial R^{t}}{\partial c^{h}} \\
-\frac{\partial R^{h}}{\partial c^{t}} & 1
\end{array}\right]\left[\begin{array}{l}
d c^{t} \\
d c^{h}
\end{array}\right]=\left[\begin{array}{cc}
\frac{\partial R^{t}}{\partial \tau} & 0 \\
0 & \frac{\partial R^{h}}{\partial Z}
\end{array}\right]\left[\begin{array}{l}
d \tau \\
d Z
\end{array}\right]
$$

Because of the stability condition (16),

$$
D=\left|\begin{array}{cc}
1 & -\frac{\partial R^{t}}{\partial c^{h}} \\
-\frac{\partial R^{h}}{\partial c^{t}} & 1
\end{array}\right|>0
$$

satisfying the conditions of the implicit function theorem. Applying that theorem, 


$$
\frac{\partial \lambda}{\partial Z}=-\frac{\partial R^{h}}{\partial Z}\left(\frac{\frac{\partial L}{\partial c^{h}}+\frac{\partial L}{\partial c^{t}} \frac{\partial R^{t}}{\partial c^{h}}}{D}\right)
$$

From the stability condition (16), the numerator of the expression in parentheses is negative. Thus,

$$
\frac{\partial \lambda}{\partial Z}>0
$$

By a similar argument,

$$
\frac{\partial \lambda}{\partial \tau}>0
$$


Table A.1

Coefficient Estimates from Alternate Specifications

Dependent Variable: Experience Premium

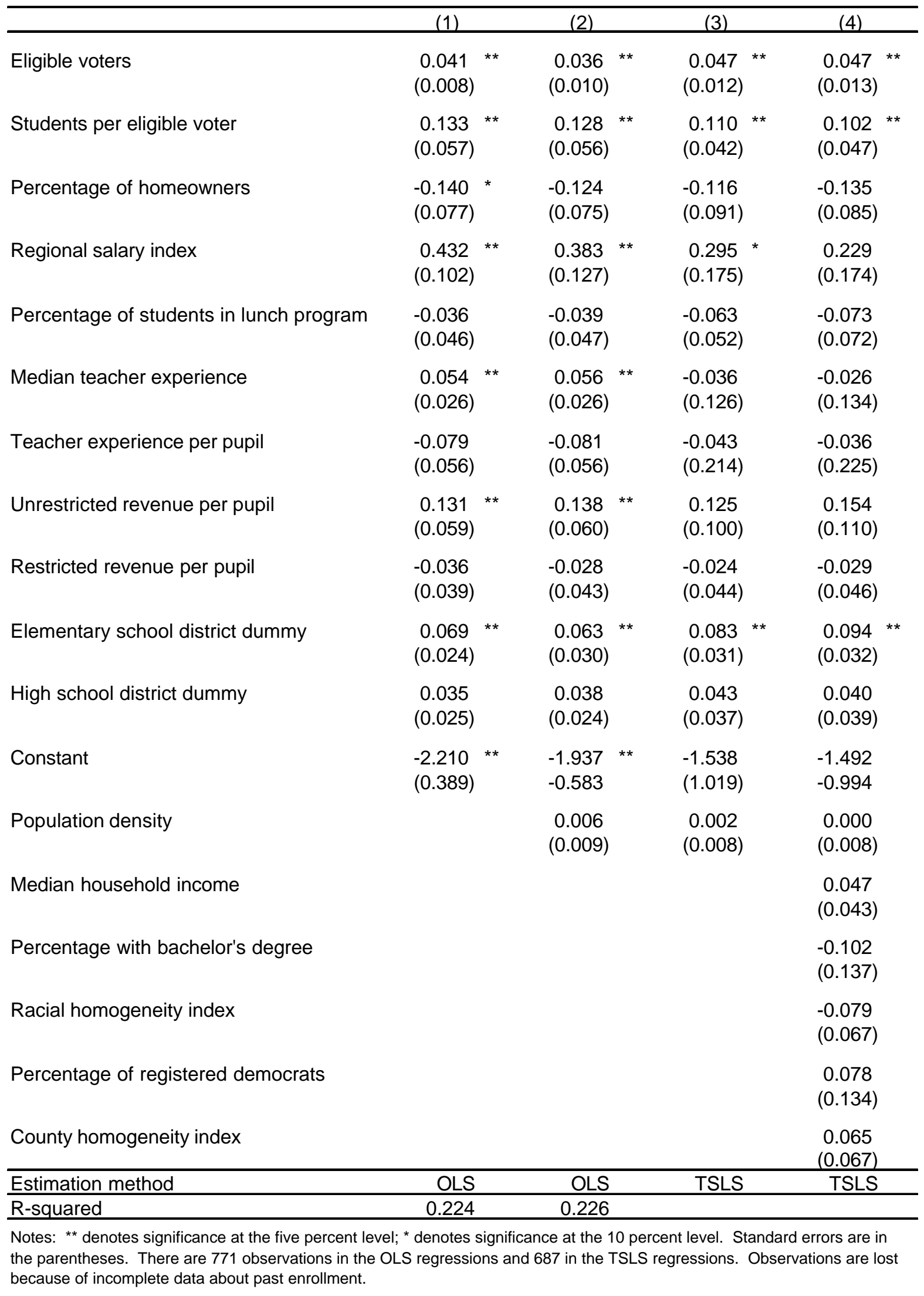

